\title{
Attitudes and Perceptions Towards Local Government Service Delivery Efforts in Limpopo Province, South Africa
}

\author{
Aklilu A. Asha \\ Lecturer, Department of Development Planning and Management, University of Limpopo, \\ aklilu.asha@ul.ac.za
}

Doi:10.5901/mjss.2014.v5n20p224

\begin{abstract}
There is an on-going debate with regard to the effectiveness of local governments in terms of service provision in South Africa. It is evident that the country has been experiencing several violent service delivery protests in different localities. Hence, this study aims to explore the attitude and perceptions of officers and community representatives regarding the current status of service delivery in Polokwane, Lepelle-Nkumpi and Aganang local municipalities in Limpopo Province. Techniques such as interviews, group discussions and questionnaire were used to collect data. The findings from interviews and discussions show that respondents have discomfort and frustration with the current level of services in their local municipalities. Furthermore, the analysis of the overall attitude indicated that the majority of the respondents uphold the view that service delivery is largely inadequate in the local municipalities under study. Likewise, the analysis on the degree of response revealed the key factors that affect the local service delivery, inter alia: limited administrative capacity to function and manage finances; huge service delivery backlogs; and insufficient incentives for performance. Therefore, it is recommended that the local municipalities should continuously assess the satisfaction level of their beneficiary community with regard to the various types of services provided by municipalities. The local municipalities should also focus on key strategic interventions such as: building their institutional capacity; improving financial management and administration; and improving incentives and stipends to the key role players of service delivery.
\end{abstract}

Keywords: Local government, service delivery, South Africa, developmental local government, Limpopo, local municipalities.

\section{Introduction}

During apartheid era, the public sector including local governments was mainly characterized by lack of people-centred development approach. It was racially divided, lacks integration and coordination and rule based command and control approach (Tshandu and Kariuki, 2010). During this system of governance, local governments were not Constitutionally safeguarded because they were perceived as structural extensions of the national and provincial governments (Williams, 2006).

The situation hindered local governments from having real power and authorities over initiating and implementing their own services and development initiatives. Moreover, the system had excluded some racial groups from decision making process and promoted discrimination and inequality (South Africa, 1998) and unequal provision of services to the local people (Thornhill, 2008). More specifically, the system had institutionalized social and economic marginalization in the country.

These situations and the shift towards the New Public Management (NPM) at global level had influenced the need to transform the role of public institutions including the local governments in South Africa to overcome the developmental challenges and accelerate service delivery ((Tshandu and Kariuki, 2010). The basic idea behind the transformation process was to devolve more decision making power to local government in order to enhance their effectiveness in service provision and development. To that end, the new democratic government has introduced various legal and policy frameworks in order to stipulate the developmental mandates of local governments. Accordingly, one of the key roles of local government is to provide basic services in sustainable way (South Africa, 1996; South Africa, 1998).

However, local governments are still struggling in terms of service provision to the previously marginalized and disadvantaged people, specifically in townships and rural areas of the country. Since the country has been experiencing several violent service delivery protests in different localities, there is an on-going debate with regard to the effectiveness of local service provision. In its working paper, Cooperative Governance and Traditional Affairs (COGTA, 2009) identified service delivery backlogs as one of the key challenges facing South African developmental local governments. The major explanations in relation to the failure of local service delivery, inter alia, lack of capacity (Kanyane, 2006), poor community 
participation (Barichievy et al, 2005; Mafunisa and Xaba, 2008), and devolution of limited power and authority (Santon, 2009).

In practice, the local authorities are struggling to meet the needs of the poor in terms of basic services. Koelble and Siddle (2013) noted that the municipal governance in South Africa is in a state of paralysis, service delivery failure, and dysfunction.

\section{Objectives}

In the light of the aforementioned context, the purpose of this study is to explore the attitude and perception of municipal officers as well as community representatives with regard to the current status of service delivery in Polokwane, LepelleNkumpi and Aganang local municipalities in Limpopo Province, South Africa. More specifically:

a) To explore the perception of respondents about the status of service delivery,

b) To analyse the degree of response in relation to the status of service delivery, and

c) To analyse the overall attitude of respondents in relation to the status of service delivery.

\section{Literature Review}

Local service delivery is a global challenge. Many countries have adopted various reforms in terms of legislations and policies in order to overcome the challenges related to adequate and quality services to the people. However, service delivery in many countries remains inadequate and fails to meet the needs of socially excluded groups (Holland et al., 2012). It is evident that many countries have been embarked in decentralisation process, yet the service delivery is still a big problem. As Conyers (2007) noted that despite the efforts to decentralise administrations functions and resources, the quantity, quality and equity of public services in Sub-Saharan Africa region remains inadequate. Likewise, Robinson (2007) indicated that the quality of public services has either declined or remained unchanged in developing countries of Africa, Asia and Latin America.

It has been argued that local governments have an important role in providing basic services to the people. It also became evident that decentralised approach can enhance local government's role in local development as long as certain key factors are taken into consideration. Ghuman and Singh (2013:9) pointed out that local governments can contribute to improve basic service provisions, namely, education, roads, sanitation, housing, irrigation, water, street light, and health in decentralised system. The authors maintained that the following factors and conditions should be taken into consideration:

a) Devolution of adequate power and responsibilities,

b) Fiscal autonomy at local level,

c) Autonomy to local governments in Human Resource Management (HRM) matters,

d) Performance based incentive structure,

e) Promotion of minimum standards to enhance quality of services,

f) Transparent decision making process,

g) Participatory governance model, and

h) Dissemination of information and accommodating the voices of citizens in policy and planning process.

In South Africa, after the democratic election of 1994, the government has adopted various strategies in relation to reforming service delivery (Tshandu and Kariuki, 2010). The notable transformation includes the establishment of a new system of developmental local government and integrated development planning to promote local service provisions.

The fundamental objective behind South Africa's reform since 1994 was to overcome developmental challenges and accelerate service delivery in order to address higher level of poverty and inequality at local level as a legacy of apartheid system (Tshandu and Kariuki, 2010). To that end, the democratic government has adopted a right based Constitutional reform in 1996. Accordingly, The Constitution of Republic of South Africa Act 108 of 1996, states that everyone, the rural and urban dweller, has the right to access to basic services including the clean drinking water, electricity, sanitation, waste removal, housing and similar items.

The constitution of democratic South Africa section 40(1) clearly identifies three interrelated, interdependent, interconnected spheres of government, namely the national, provincial and local government. It also identifies powers and functions of these local authorities as spheres of government not subordinate to other spheres of government (South Africa, 1996).

According to the Constitution, local governments have a significant role to play in respect of promoting the social and economic development of local communities, and participating in national and provincial development programmes. 
In Section (151) the constitution provides the establishment of new system of local government:

- The local sphere of government to consist of municipalities which must be established for the whole territory of the republic;

- The legislative and executive authority of a municipality to be vested up on its municipal council;

- A municipality has the right to govern on its own initiations, the local government affairs of its community subject to national and provincial legislations as provided in the constitution; and

- The national and provincial spheres may not compromise or impede municipality's ability or right to exercise its powers or perform its functions.

Concerning the role of local government, section 152 of the constitution describes the primary objectives for the newly to be established local governments. The constitution requires local government to give priority to the basic needs of community in their administration, budgeting and planning processes in order to promote social and economic development (section 153).

One of the key roles includes providing basic services in sustainable way. According to the constitution, the local government in South Africa has got three types of municipalities. Section 155 (1) provides for the following types of municipalities:

- Category 'A' also called 'metropolitan municipality' is a municipality that has exclusive municipal executive and legislative authority in its area of jurisdiction.

- Category 'B' or 'local municipality' is a municipality that shares a municipal executive and legislative authority in its area of jurisdiction with category 'C' municipality within whose area it falls.

- Category ' $C$ ' or 'district municipality' is a municipality that has municipal executive and legislative authority in area that includes more than one municipality.

Hence, local government institutions are close to community and have great responsibility on improving the living standard of the people. Besides the constitution, national government put in place different types of policies and legislations to guide the transformation towards decentralised service delivery such as the White Paper on Local Government 1998 (South Africa, 1998) and Municipal Systems Act 2000 (South Africa, 2000). As part of its mandate to guide and support local development process in municipalities of South Africa, the national governments further clarified the mandates of local government as identified in the constitution of 1996. The objective is to identify priority areas and motivate local government's initiatives for social and economic transformation at grass root level development. Additionally, national government has to play supervision and monitoring roles to assist the functions of local authorities.

Developmental local government, according to the White Paper, refers to a local government that must be committed to work with citizens and groups within the community to find sustainable ways to meet their social, economic and material needs an improve the quality of their lives. It should target especially those members and groups within communities that are marginalized or excluded, such as women, disabled people and very poor people (South Africa, 1998). Therefore, improving participation, social and economic development and sustainable approaches, and prioritising the needs of the poor are the key development agendas for local authorities. Provision of services, promotion of local economic development, and community empowerment and redistribution are some of the key responsibilities of developmental local government. Developmental Local Government has the policy mandate to maximize social development and economic growth. A municipality must make sure that the people and the economy in its area are healthy and well taken care of. In particular, municipalities are responsible for providing services that meet the basic needs of the poor in their communities, in a cost-effective and affordable manner (South Africa, 1998). It has been clear that the local municipalities in South Africa are mandated legally to provide adequate services to the people.

Despite the presence of legislations and policies as well as the measures taken to reform the public sectors in South Africa, the success of these reforms has been limited as a result of fragility of state bureaucracy and capacity limitations (Tshandu and Kariuki, 2010). It is clear that the country has been experiencing several protests by the poor in different localities. Alexander (2010) indicates such protest as 'the rebellion of the poor' and he argues that these protests are mainly linked to the disappointment with inadequate service delivery and lack of accountability by local councilors. Inadequate investment in public services, underfunding in key areas (e.g. housing), post-apartheid government neoliberal policies and the political deployment are cited as the key sources of the problems (Alexander, 2010). Edward (2010) adds that the service delivery crisis, which is affecting two-third of the local municipalities in South Africa, is mainly caused by institutional shortcomings such as incoherent national policies, lack of enforcement and lack of skills (e.g. customer care and relations, financial controls, technical competencies in core areas of electrification, basic water, sanitation and refuse removal). 


\section{Methodology}

The study area, Limpopo Province, is one of the nine provinces officially recognised in South Africa. The Province is divided into five municipal districts and sub-divided into twenty five rural and urban local municipalities. Geographically, this Province is situated at the north eastern corner of the country. It shares the border with three countries such as Botswana, Zimbabwe and Mozambique. It is also the main gateway to other countries in further field in Sub-Sahara. According to Statistics South Africa (SSA, 2012), the Limpopo Province has a total land area of 125, 754 square kilometres which forms 10.3 percent of the total land area in South Africa. The population of the Province was estimated at 5404868 people which accounts for 10.4 percent of the total population of the country. Regarding the socio-economic situation, the percentage of population and of the total number of households in the Province is steadily growing and this poses additional challenges in service provisions and development at local level.

The study employed both quantitative and qualitative approaches. The sampling techniques involved stratified and purposive methods to identify the local municipalities as well as participants of the study for gathering field data. The data was collected by employing a variety of methods including questionnaire, individual interview, group discussion and analysis of available documents.

The quantitative analysis was carried out using descriptive statistics (frequencies, percentages, mean and standard deviation) whereas the qualitative analysis involved field notes, transcription of field notes, categorising the data and interpretation processes.

\section{Key Findings}

\subsection{Biographical Details of Respondents}

The study was undertaken by engaging 83 officers and community representatives from the three local municipalities such as Polokwane, Lepelle-Nkumpi and Aganang. A total of 30 participants participated during the field interview and discussions. Out of the total 30 participants, about $24(80 \%)$ of the respondents were male and $6(20 \%)$ female. Regarding the level of education of participants, $12(40.0 \%)$ hold diplomas and above, $13(43.3 \%)$ completed only grade 12 and the rest, $5(16.7 \%)$ had grade 11 or less. Regarding the positions of participants, about 17 (56.7\%) were community representatives such as ward committee members, traditional leaders, CBOs and private sectors while 13 (43.3\%) were municipal officers and workers including IDP officers, LED officers, PMS Officers and CDWs.

On the other hand, a total of 53 respondents were involved in filling the questionnaire for this study. Out of the total 53 respondents, $34(64.2 \%)$ were male and $19(35.8 \%)$ were female. Regarding age, the mean age of the respondents was 38 years with a standard deviation of 8.8 and it ranges from 19 up to 60 years. Out of 53 respondents, 10 (18.9\%), $15(28.3 \%)$ and $28(52.8 \%)$ had grade 11 or less, grade 12, diploma and above, respectively. Out of 53 respondents, 44 $(83.0 \%)$ and 9 (17.0\%) were municipal officers/ workers and community representatives, respectively. The mean year of experience of the respondents was 5 years with a standard deviation of 12.3 and it ranges from 1 up to 9 years.

\subsection{Perceptions of Respondents about the Status of Service Delivery}

The study revealed that the provision of basic services to the beneficiaries in the local municipalities was largely inadequate. During the field interview and group discussion, respondents from Lepelle-Nkumpi indicated their discomfort with the current level of services in their municipalities. These respondents indicated that their local municipality fails to give feedbacks to communities regarding services and infrastructure. Respondents reflected as follow:

"Lack of adequate services frustrates the ward committee because we do not have answers...in some cases water projects are finalized but there is no water and likewise the electricity is installed but no power"

According to the respondents, their frustration was linked to: a) The road infrastructure which is not conducive and still remaining behind, b) Shortage of water as a serious problem to the community, especially in wards for certain periods of time due to pipe bursting, and c) The problem of electricity backlogs and electrification of RDP houses.

Other respondents from Polokwane also pointed out the need to further decentralize services and infrastructure to cluster level. Despite the local municipality has provided services and completed infrastructural projects, the contribution so far was not satisfactory. They expressed this sentiment as follow: 
"'The role of the municipality is to provide services but the contribution is not satisfactory...yet there are many projects which are completed, examples include toilet facilities, electrification, road construction, water projects, and library and sport grounds."

"The town (Polokwane) is growing but the supply of water is not enough...currently the municipality outsources water from Tzaneen area"

The respondents indicated that: a) Supply of water is not enough, b) Infrastructures are damaged (pipeline and the electric wires) by individuals, c) Waste management in rural areas is very week, and d) Electricity is not reliable.

\subsection{Analysis of Degree of Response in relation to the Status of Service Delivery}

An attempt was made to assess the degree of response, the mean and standard deviation of the responses related to service delivery at the local municipalities (Table 1). The construct 'the role in service delivery' consisted of seven statements listed as follow:

- Statement B1- Local municipality lacks ability to play crucial role in service delivery.

- Statement B2- Service delivery is affected by limited administrative capacity to function and manage finances.

- Statement B3 - A poor incentive for performance is affecting service provision in the municipality.

- Statement B4 - There is a lack of coordination among sector departments with respect to service delivery.

- Statement B5- The local municipality is faced with shortage of financial resources, resulting in service delivery disruption.

- Statement B6- The local municipality has huge service delivery backlogs.

- Statement B7- There is dissatisfaction from communities with regard to quality of services by the municipality.

As shown in Table 1, the highest (mean=3.70) of statement B2 which states 'service delivery is affected by limited administrative capacity to function and manage resources', implies that service delivery is highly affected by limited administrative capacity, when compared to the other items. The second item with high mean is the statement B6 (mean=3.63) 'the local municipality has huge service delivery backlogs'. This statement also suggests that the local municipality has huge service delivery backlogs. The third highest mean (3.60), i.e. statement B3 "a poor incentive for performance is affecting service provision in the municipality" also reveals the need to encourage and motivate those who are working with the community.

Table 1: Degree of response related to service delivery $(n=53)$

\begin{tabular}{|c|ccccccc|}
\multicolumn{1}{c|}{ Items } & Strongly disagree & Disagree & Undecided & Agree & Strongly Agree & Mean & SD \\
& 15 & 32.5 & 7.5 & 22.5 & 22.5 & 3.05 & 1.449 \\
Statement B1 & 7.5 & 12.5 & 10.0 & 42.5 & 27.5 & 3.70 & 1.224 \\
Statement B2 & 7.5 & 17.5 & 15 & 27.5 & 32.5 & 3.60 & 1.317 \\
Statement B3 & 7.5 & 25.0 & 7.5 & 25.0 & 35.0 & 3.55 & 1.395 \\
Statement B4 & 15.0 & 12.5 & 7.5 & 37.5 & 27.50 & 3.50 & 1.414 \\
Statement B5 & 5.0 & 17.5 & 15.0 & 35.0 & 27.5 & 3.63 & 1.213 \\
Statement B6 & 5.0 & 20.0 & 12.5 & 37.5 & 25.0 & 3.58 & 1.217 \\
Statement B7 & & & &
\end{tabular}

Source: own survey data, 2014

The aforementioned analysis on the degree of response in relation to the local service delivery reveals that the service delivery at local level is insufficient mainly due to limited administrative capacity and poor incentive for performance.

The result can be further detailed by considering items from B1- B7 as follow.

- Statement B1- Local municipality lacks ability to play crucial role in service delivery. According to Table 1, the total of $48 \%$ of respondents either disagreed or strongly disagreed; $8 \%$ were undecided; $23 \%$ agreed; while $23 \%$ strongly agreed with the above statement. The large proportion of respondents who did not confirm the statement suggests that local governments were contributing for improved basic services at the local level. On the other hand, the significant number of respondents also supported the statement. The results indicate that there is still much to be done to improve the ability of local authorities to deliver adequate services to its citizens. 
- Statement B2- Service delivery is affected by limited administrative capacity to function and manage finances. The above analysis in Table 1 shows that only $8 \%$ of respondents strongly disagreed; $13 \%$ agreed; $10 \%$ were undecided; $43 \%$ agreed; while $28 \%$ strongly agreed with the above statement. The result shows that the majority of the respondents support the statement. This may indicate that the maladministration and mismanagement of financial resources at municipal level could affect the provision of services to the local people.

- Statement B3 - A poor incentive for performance is affecting service provision in the municipality. The finding in Table 1 shows that only $8 \%$ of respondents strongly disagreed; $18 \%$ agreed; $15 \%$ were undecided; $28 \%$ agreed; while $33 \%$ strongly agreed with the above statement. Based on the finding, it can be argued that the large proportion of respondents confirm the statement. This means inadequate incentives at the local level may affect the effort towards provision of adequate services to the community. For example, the ward committee members complain about the inadequacy and delay of their stipends which of course influence negatively on their performance.

- Statement B4 - There is a lack of coordination among sector departments with respect to service delivery. The aforementioned analysis in Table 1 shows that only $8 \%$ of respondents strongly disagreed; $25 \%$ agreed; $8 \%$ were undecided; $25 \%$ agreed; while $35 \%$ strongly agreed with the above statement. From this analysis it can be concluded that the largest proportion of respondents confirms the statement. The result shows that weakness in coordination of sector plans and projects may influence the effectiveness in providing services to the community at large.

- Statement B5- The local municipality is faced with shortage of financial resources, resulting in service delivery disruption. Table 1 shows that a total of $35 \%$ of respondents either disagreed or strongly disagreed; $8 \%$ were undecided; $38 \%$ agreed; while $26 \%$ strongly agreed with the above statement. The finding shows that the highest proportion of respondents support the statement. The high proportion of respondents who agreed with the statement indicates that shortage of financial resources may negatively influence service provision to the community. For instance, rural local municipalities like Lepele-Nkumpi and Aganang have low income base as the majority of their population depends on social security.

- Statement B6- The local municipality has huge service delivery backlogs. According to Table 1, only 5\% of respondents strongly disagreed; $18 \%$ disagreed; $15 \%$ were undecided; $35 \%$ agreed; while altogether $28 \%$ strongly agreed with the above statement. The result indicates that the highest proportion of respondents confirm the statement. The high proportion of respondents who agreed with the statement shows that the growing number of beneficiaries is adding on existing service delivery backlogs and this may negatively influence service provision to the community. For instance, urban municipalities like Polokwane have been facing a growing demand for services due to several reasons including migration.

- Statement B7- There is dissatisfaction from community with regard to quality of services by the municipality. The above analysis in Table 1 shows that, only $5 \%$ of respondents strongly disagreed; $20 \%$ disagreed; $13 \%$ were undecided; $38 \%$ agreed; while altogether $25 \%$ strongly agreed with the above statement. Based on the finding, it can be argued that the majority of the respondents supported the response. The high proportion of respondents who agreed with the statement suggests that there is a concern about the level and quality of services provided by the local municipalities. Despite the existence of dissatisfaction, the local municipalities under study have not faced violent service delivery protests which have been occurring in other parts of the country. However, this does not mean that communities are satisfied with the current service provision.

\subsection{Analysis of the Overall Attitude of Respondents on the Status of Service Delivery}

The analysis and results of attitudinal assessment on the role in service delivery in the local municipalities is presented below. 
Table 2: The attitude of respondents on the status of service delivery by categories of local municipalities ( $n=53)$

\begin{tabular}{|c|c|c|c|c|c|c|c|c|}
\hline \multirow{2}{*}{ Category of local municipality } & \multicolumn{2}{|c|}{ SD \& DA } & \multicolumn{2}{c|}{ Undecided } & \multicolumn{2}{c|}{ SA \& AG } & \multicolumn{2}{c|}{ Total } \\
\cline { 2 - 9 } & Freq. & $\%$ & Freq. & $\%$ & Freq. & $\%$ & Freq. & $\%$ \\
\hline Urban (Polokwane) & 4 & 7.55 & 1 & 1.89 & 10 & 18.87 & 15 & 28.31 \\
\hline Rural (Lepelle-Nkumpi and Aganang) & 9 & 16.98 & 5 & 9.43 & 24 & 45.28 & 38 & 71.69 \\
\hline Total & 13 & 24.53 & 6 & 11.32 & 34 & 64.15 & 53 & 100.00 \\
\hline
\end{tabular}

Source: own survey, 2014; SD= Strongly Disagree; DA=Disagree; SA= Strongly Agree; AG= Agree.

The analysis on overall attitude of respondent's related to service delivery in the local municipalities indicates that 34 $(64 \%)$ of the respondents tend to support the view that the role of local municipalities in service delivery is limited due to various challenges while $6(11 \%)$ of them remained undecided. The rest $13(25 \%)$ of them tend to disagree with the above view (Table 2).

The result is similar along the categories of local municipalities. Among the 15 respondents from urban categories, $10(19 \%), 1(2 \%)$ and $4(8 \%)$ of them have confirmed, undecided and did not support the idea, respectively. On the other hand, among the respondents who belong to rural categories, 24 (45\%), 5 (9\%) and 9 (17\%) have confirmed, undecided and did not support the idea, respectively (Table 2).

\section{Conclusion}

In conclusion, the basic service delivery was largely inadequate in the local municipalities under study. The findings from interviews and group discussions indicated that community members have shown discomfort and frustration with the current level of services in their local municipalities. The analysis of the overall attitude in relation to the local municipalities role in service delivery indicated that the majority of the respondents tend to support the view that service delivery role is limited due to various challenges. Additionally, the analysis on the degree of response also reveals that the service delivery at the local level is mainly affected by the following factors: limited administrative capacity to function and manage finances; huge service delivery backlogs; and a poor incentive for performance.

Therefore it is recommended that the local municipalities should focus on the following strategic interventions: building the institutional capacity; improving financial management and administration; improving incentives and stipends to the key role players; and promote improved coordination among sector departments within the municipality. Moreover, local municipalities need to continuously assess the satisfaction level of their beneficiary community in order to improve the quality of services at the local level.

\section{References}

Alexander, P. (2010). Rebellion of the poor: South Africa's service delivery protests- a preliminary analysis. Review of African Political Economy, 37, 25-40.

Barichievy, K., Piper, L. \& Parker, B., (2005). Assessing 'Participatory Governance' in local government: a case study of two South African cities. Politeia, 24, 370-393.

Conyers, D. (2007). Decentralisation and service delivery: lessons from Sub-Saharan Africa. IDS Bulletin vol. 38, no. 1, Institute of Development Studies, Sussex, UK.

Cooperative Governance and Traditional Affairs (COGTA). (2009). State of local government in South Africa. Pretoria: COGTA.

Edward, L. (2010). Institutional obstacles to service delivery in South Africa. Journal of African Studies, 36, 565-589.

Ghuman, B.S. and Singh, R. (2013). Decentralisation and delivery of public services in Asia. Policy and Society, 32, 7-21.

Holland, J., Ruedin, L., Scott-Villers, P., and Sheppard, H. (2012). Tackling the governance of socially inclusive service delivery. Public Management Review, 14, 181-196.

Kanyane, M.H. (2006). Municipal skills challenge for accelerated service delivery in South Africa. Journal of Public Administration, conference Proceedings.

Koelble, T. and Siddle, A. (2013). Why decentralisation in South Africa has failed? International Journal of policy, administration, and institutions, 26, 343-346.

Mafunisa, M. \& Xaba, B. (2008). Public Participation and the Integrated Development Planning: The Case of Limpopo province. Journal of Public Administration, 43, 452-460.

Robinson, M. (2007). Introduction: decentralising service delivery? Evidences and policy implications. IDS Bulletin vol. 38, no. 1, Institute of Development Studies, Sussex, UK.

South Africa. (1996). Constitution of the Republic of South Africa. Pretoria: Government Printers. 
South Africa. (1998). White Paper on Local Government. Pretoria: Government Printers.

South Africa. (2000). Local Government Municipal Systems Act 32 of 2000. Pretoria: Government Printer.

Statistics South Africa (SSA). (2012). Limpopo provincial profile. Pretoria: SSA. Available : www.statssa.gov.za/publications/ Report00.../Report-00-91-092004.pdf (21/01/2014)

Tshandu, Z and Kariuki, S. (2010). Public administration and service delivery reforms: a post- 1994 South African case. South African Journal of International Affairs, 17, 189-208.

Thornhill, C. (2008). Transformed local government system. Journal of Public Administration, 43, 492-511.

Williams, J. (2006). Community participation: lessons from post-apartheid South Africa. Policy Studies, 27, 197-217. 